\title{
Novel strategies to fight Candida species infection
}

\author{
Maria Elisa Rodrigues, Sónia Silva, Joana Azeredo, and Mariana Henriques \\ CEB - Centre of Biological Engineering, LIBRO - Laboratório de Investigação em Biofilmes Rosário Oliveira, University of Minho, Braga, Portugal
}

\begin{abstract}
In recent years, there has been a significant increase in the incidence of human fungal infections. The increase in cases of infection caused by Candida species, and the consequent excessive use of antimicrobials, has favored the emergence of resistance to conventional antifungal agents over the past decades. Consequently, Candida infections morbidity and mortality are also increasing. Therefore, new approaches are needed to improve the outcome of patients suffering from Candida infections, because it seems unlikely that the established standard treatments will drastically lower the morbidity of mucocutaneous Candida infections and the high mortality associated with invasive candidiasis. This review aims to present the last advances in the traditional antifungal therapy, and present an overview of novel strategies that are being explored for the treatment of Candida infections, with a special focus on combined antifungal agents, antifungal therapies with alternative compounds (plant extracts and essential oils), adjuvant immunotherapy, photodynamic therapy and laser therapy.
\end{abstract}

\section{Keywords}

Antifungal agents, immunotherapy, low-level laser therapy, natural compounds, photodynamic

\section{History}

Received 7 May 2014

Revised 2 October 2014

Accepted 6 October 2014

Published online 7 November 2014

\section{Introduction}

The incidence and prevalence of invasive fungal infections caused by yeasts of the Candida genus is a major problem, especially in immunocompromised patients or those hospitalized with serious underlying diseases (Arendrup et al., 2005; Enoch et al., 2006; Espinel-Ingroff et al., 2009; Gahn et al., 2007; Ruhnke et al., 2011; Sims et al., 2005; Van de Veerdonk et al., 2010).

Candida species are frequent colonizers of the skin and mucous membranes of animals and their dissemination in nature is widespread (Ruhnke, 2006; Ruhnke et al., 2011). There are over 350 heterogeneous Candida species, but only a few have been implicated in human disease: Candida albicans, Candida dubliniensis, Candida parapsilosis, Candida tropicalis, Candida glabrata, Candida kefyr (pseudotropicalis), Candida lusitaniae, Candida krusei, Candida guilliermondii, Candida utilis, Candida lipolytica, Candida famata, Candida haemulonii and Candida rugosa (Ruhnke, 2006; Ruhnke et al., 2011; Williams et al., 2011). Although C. albicans remains as the most common pathogen, non-Candida albicans Candida (NCAC) species are now increasingly associated with invasive candidiasis (Baran et al., 2001; Diekema et al., 2002; Macphall et al., 2002; Pappas et al., 2004; Pfaller et al., 1998; , Trick et al., 2002).

The spectrum of diseases caused by Candida consists of superficial and invasive Candida infections. These infections range from non-life-threatening mucocutaneous illnesses to

Address for correspondence: Mariana Henriques, Centre of Biological Engineering (CEB), University of Minho, 4710-057 Braga, Portugal. Tel: +351 253604 401. Fax: +351 253604 429. E-mail: mcrh@deb.uminho.pt invasive processes that may involve virtually any organ (Blumber et al., 2001; Kojic \& Darqouiche, 2004; Kuhn et al., 2002a; Michalopoulos et al., 2003; Munoz et al., 2000; Pappas et al., 2004; Ruhnke et al., 2011; Rüping et al., 2008; Tumvarello et al., 2007; Wey et al., 1989; Wenzel, 1995; Williams et al., 2011). A number of factors have been implicated in the significant increase of incidence of human fungal infections, but it is generally accepted that the main influences relate to the more widespread provision of new medical practices, such as immunosuppressive therapy and use of broad spectrum antibiotics, central venous catheters, parenteral nutrition, invasive surgical procedures and indwelling medical devices (e.g. dental implants, catheters, heart valves, vascular bypass grafts, ocular lenses, artificial joints and central nervous system shunts) which can act as substrates for biofilm formation (Blumber et al., 2001; Michalopoulos et al., 2003; Muñoz et al., 2000; Ruhnke et al., 2011; Rüping et al., 2008; Wenzel, 1995; Wey et al., 1989; Williams et al., 2011). Indeed, most manifestations of candidiasis are in fact associated with the formation of Candida biofilms on surfaces, and this phenotype is implicated with infection at both the mucosal and systemic sites (Jabra-Rizk et al., 2004).

Biofilms, represent the most prevalent type of microbial growth in nature, and consist in a complex surface-associated cell populations embedded in an extracellular matrix (ECM) that posses distinct phenotypes compared to their planktonic cell counterparts (Fanning \& Mitchell, 2012). Biofilm cell communities are more resistant to antifungal drugs than planktonic cells and can create a source of persistent infection (Chandra et al., 2001). Contributing factors include biofilm structural complexity, presence of ECM, metabolic 
heterogeneity intrinsic to biofilms and biofilm-associated up-regulation of efflux pump genes. The actual fold increase in resistance varies with both the drug and species (Chandra et al., 2001; Fanning \& Mitchell, 2012).

Biofilm-associated Candida infections show uniform resistance to a wide spectrum of the currently available conventional antifungal agents, which implies that antimicrobial drugs that specifically target biofilm-associated infections are needed (Jabra-Rizk et al., 2004).

\section{Epidemiology}

Invasive candidiasis, mostly candidaemia, is a serious and potentially lethal disease. It is associated with a high global mortality rate, ranging from $36 \%$ to $63 \%$ in different patient groups (Gudlaugsson et al., 2003; Guery et al., 2009; Kullberg et al., 2011; Marchetti et al., 2004; Pappas et al., 2003; Tortorano et al., 2004; Van de Veerdonk et al., 2010; Wisplinghoff et al., 2004; Zaoutis et al., 2005), and represents a significant burden on the public health system in terms of patient management and healthcare costs (Kullberg et al., 2011; Tortorano et al., 2004). Of particular significance is the fact that approximately half of all Candida infections now occur in intensive-care units (ICUs; Kullberg et al., 2005, 2011; Vincent et al., 1998).

Of the Candida species isolated from humans, C. albicans is the most prevalent in both health and disease. Mycological studies have shown that candidaemia is most often caused by $C$. albicans (45-65\%), but there has been a significant pathogen shift towards other Candida species over the past few years in some patient groups (Arendrup et al., 2008; Dupont et al., 2009; Kullberg et al., 2011; Tortorano et al., 2004; Trick et al., 2002). In particular, C. glabrata (15-30\%), C. tropicalis (10-30\%), C. parapsilosis, C. krusei, C. lusitaniae and $C$. guilliermondii have been implicated in invasive candidiasis (Ruhnke et al., 2011; Tortorano et al., 2004; Viscoli et al., 1999).

A shift in the etiology of candidaemia has been documented in Slovakia and France, where the rate of NCAC species, especially C. glabrata, increased in 10 years from $0 \%$ to $46 \%$ (Krcméry \& Kovačičová, 2000; Ruhnke et al., 2011; Sendid et al., 2006). In contrast, in Spain and Italy, C. parapsilosis is the predominant agent of candidaemia after $C$. albicans (Almirante et al., 2006; Bassetti et al., 2007; Ruhnke et al., 2011). A study in Denmark documented an increase in the incidence of candidaemia, from 2003 to 2004, with C. glabrata being second after C. albicans (Almirante et al., 2006; Bassetti et al., 2007; Ruhnke et al., 2011). These increased prevalence of NCAC species in disease could also reflect their inherently higher level of antifungal drug resistance (González et al., 2010; Williams et al., 2011) compared with C. albicans, as this would promote their persistence, possibly to the detriment of $C$. albicans, in mixed-species infections treated with traditional antifungal agents ( Colombo et al., 1999; Kullberg et al., 2011; Rocco et al., 2000; Williams et al., 2011). The changing epidemiology has been partly attributed to selection of less sensitive Candida species, due to the widespread use of fluconazole as a prophylactic and therapeutic agent (Colombo et al., 1999; Kullberg et al., 2011; Rocco et al., 2000).
The relatively high rate of infection by Candida species in ICUs, the increasing prevalence of NCAC species, and the associated mortality suggest that new treatment approaches are required. Findings from numerous prospective and retrospective studies indicate that optimizing and reducing the delay of antifungal therapy reduces attributable mortality in patients with candidemia whereas inappropriate antifungal therapy is a significant predictor of mortality (Antoniadou et al., 2003; Bassetti et al., 2007; Blot et al., 2002; Dupont et al., 2009; Ibrahim et al., 2000; Morrell et al., 2005).

\section{Standard treatment}

The current standard treatment of Candida infections consists of antifungal agents licensed from four different groups: polyenes, azoles, echinocandins and nucleoside analogues (Caillot et al., 1994; Ruhnke et al., 2011; Van de Veerdonk et al., 2010).

Polyene antifungal agents (e.g. nystatin and amphotericin B) exert their fungicidal activity by causing porosity on the fungal cell membrane followed by interaction with the membrane ergosterol and subsequent loss of cytoplasmic content (Henry et al., 2000; Onyewu \& Heitman, 2007; Sanglard et al., 2003; Williams et al., 2011). A second proposed mechanism of action involves a cascade of oxidation reactions and interactions with lipoproteins that impair membrane permeability through the release of free radicals (Barwicz et al., 1998; Brajtburg et al., 1990; Onyewu \& Heitman, 2007).

Nystatin was the first antifungal agent reported and is available in topical creams and oral washes for treatment of cutaneous and mucocutaneous candidiasis. For its turn, Amphotericin B exhibits broad spectrum antifungal activity against a variety of pathogenic fungi (Andes, 2003; Onyewu \& Heitman, 2007), but its clinical utility is limited by a severe nephrotoxicity (Luber et al., 1999; Onyewu \& Heitman, 2007; Sawaya et al., 1995). Indeed, the affinity of Amphotericin B for cholesterol, the main sterol of mammalian cell membranes, is believed to cause alterations in the membrane permeability of renal tubules and vasculature, contributing to toxicity (Deray, 2002; Onyewu \& Heitman, 2007). Furthermore, this antifungal has a poor oral and intramuscular absorption, and is consequently formulated as a micellar suspension solubilized in deocycholate (D-AMB) or as a lipid formulation liposomal amphotericin B (L-AMB), amphotericin B lipid complex (ABLC) or amphotericin B colloidal dispersion (ABCD; Caillot et al., 1994; Ruhnke et al., 2011).

Despite their wide use over several decades, the actual incidence of Candida resistance to polyenes is rare, but can sometimes arise through a reduction in the ergosterol content of the cell membrane (Sanglard et al., 2003; Williams et al., 2011).

Azole antifungal agents are fungistatic through interference with the fungal cytochrome P450-dependent enzyme lanosterol $14 \alpha$-demethylase (key enzyme in the biosynthesis of ergosterol), which leads to an accumulation of aberrant sterol intermediates and depletion of ergosterol in the fungal cell membrane (Bossche et al., 1987; Henry et al., 2000; Onyewu \& Heitman, 2007; Williams et al., 2011). 
The first azoles developed were the imidazoles (miconazole and ketoconazole) for the systemic treatment of human mycoses, followed by the first-generation triazoles (fluconazole and itraconazole; Onyewu \& Heitman, 2007). The imidazoles can be used to treat invasive disease, but are most effective as topical therapies against cutaneous and mucocutaneous infections (Kyle \& Dahl, 2004; Onyewu \& Heitman, 2007). Both fluconazole and itraconazole are well absorbed through the gut, which means that oral administration is an effective mean of systemic delivery. Fluconazole has also a good safety profile when given systemically, with few side effects (Brammer et al., 1990; Onyewu \& Heitman, 2007; Williams et al., 2011). The low-toxicity profile, favorable pharmacokinetics and general efficacy of fluconazole have made it the predominant prophylactic and primary treatment choice for invasive candidiasis for the past 20 years (Onyewu \& Heitman, 2007). However, since the triazoles fluconazole and itraconazole have limitations related to their spectrum of antifungal activity and their tolerability, efforts to develop improved triazoles have led to the regulatory approval of voriconazole (approved by the FDA in 2002) and posaconazole (approved by the FDA in 2006) (Bink et al., 2011; Katragkou et al., 2008).

Certain Candida species are inherently resistant to azole antifungals, and acquired resistance has also emerged in recent years (Williams et al., 2011). The latter has mostly emerged due to the inadvertent selection of resistant subpopulations during exposure to azoles (Onyewu \& Heitman, 2007; White et al., 1998).

Echinocandins (caspafungin, micafungin and anidulafungin) are the most recent advances in antifungal drug development. These fungicidal compounds are semi-synthetic amphiphilic lipopeptides composed of a cyclic hexapeptide core linked to a variably configured lipid side chain (Onyewu \& Heitman, 2007). Echinocandins have a unique mechanism of action that consists of the inhibition of the $\beta-1,3-\mathrm{D}$-glucan synthase, a predominant polysaccharide component of the Ascomycete cell wall that maintains osmotic integrity and is involved in cell division and growth. These three echinocandins demonstrate a broad and similar spectrum of in vitro and in vivo activity against most Candida species (Douglas, 2001; Espinel-Ingroff et al., 2009; Onyewu \& Heitman, 2007; Pfaller et al., 2008).

Caspofungin, anidulafungin and micafungin are all well tolerated without serious adverse effects (Morrison, 2006; Onyewu \& Heitman, 2007). However, the large size of these compounds precludes oral formulations, and they are currently only available for intravenous administration (Onishi et al., 2000; Onyewu \& Heitman, 2007). Each agent has achieved therapeutic efficacy comparable to previously established standard agents. In a study of adults with invasive candidiasis, caspofungin treatment was equivalent to, but better tolerated than amphotericin B (Mora-Duarte et al., 2002; Onyewu \& Heitman, 2007). Currently, caspofungin is regarded as reasonable initial treatment for invasive Candida infections except for C. parapsilosis, which has demonstrated less in vitro sensitivity (Onyewu \& Heitman, 2007; Saravolatz et al., 2003).

Echinocandin drugs demonstrate fungicidal activity and low incidence of resistance (Onyewu \& Heitman, 2007). Nevertheless, as newer drugs, long-term studies are not yet available, and significant resistance mechanisms may emerge in the future (Onyewu \& Heitman, 2007).

The group of nucleoside analogues is solely composed of flucytosine. This antifungal agent is only used as a part of a combination regimen due to the rapid emergence of resistance against it (Francis \& Walsh, 1992; Ruhnke et al., 2011; Viviani, 1995). This is the only systemically used antifungal for which therapeutic drug monitoring is established to avoid toxic effects (Francis \& Walsh, 1992; Pasqualotto et al., 2007; Ruhnke et al., 2011).

In spite of the myriad of antifungal agents available, the frequency of treatment failure is considerable. Indeed, in the last few years, Candida species have evolved multiple molecular strategies to exert drug resistance. The increase in cases of infection caused by Candida strains, and the consequent excessive use of antimicrobials, has favored the emergence of resistance of these yeast species to conventional antifungal agents over the past decades (Onyewu \& Heitman, 2007; White et al., 2002). Nowadays, new approaches are needed to improve the outcome of patients suffering from Candida infections, because it seems unlikely that the established standard treatment will drastically lower the morbidity of mucocutaneous Candida infections and the high mortality associated with invasive candidiasis (Van de Veerdonk et al., 2010).

Therefore, this review will discuss the last advances in the traditional antifungal therapy, and present an overview of novel strategies for the treatment of Candida infections, with a special focus on combined antifungal agents, antifungal therapies with alternative compounds (extracts of plants and isolated essential oils), adjuvant immunotherapy, photodynamic therapy and laser therapy.

\section{Candida infection alternative therapy}

\section{Combining antimicrobial agents therapy}

In spite of the myriad of antifungal agents available, as mentioned above, the frequency of treatment failure is considerable, underscoring the necessity for new treatment strategies. In vitro experiments suggest that combinations of these agents might improve the antifungal efficacy (Baltch et al., 2008; Tobudic et al., 2010a; Van de Veerdonk et al., 2010). To note, for example, the synergistic effects obtained recently between newer and more traditional antifungal agents both in vitro and in vivo (Lewis \& Kontoyiannis, 2001).

There are several predictable advantages in combinational antifungal therapy, which include a wider spectrum and potency of drug activity, faster antifungal effect, synergy, lower dosing of toxic drug and reduced risk of antifungal resistance. However, although the use of agents with different mechanisms of action is a hallmark in current medical therapies, the combinations have to be tested as they may be antagonistic or clinically indifferent with additive side effects (Lewis \& Kontoyiannis, 2001).

There are several studies reporting positive results of synergistic combinations. Recently, Tobudic et al. (2010b) studied the in vitro activity and synergism of the combination of amphotericin B and either caspofungin or posaconazole against $C$. albicans biofilm cells. The combination of amphotericin $\mathrm{B}$ and pozaconazole yielded synergism against 
biofilms of various $C$. albicans isolates (Bink et al., 2011; Tobudic et al., 2010b). Caspofungin also demonstrated synergistic effects in combination with amphotericin B, which binds to membrane sterols. The mechanisms of synergic or additive effects for these agents are likely to be the inhibition of $(1,3)-\beta$-D-glucan formation by caspofungin leading to cell wall damage, that would allow amphotericin B easier access to the fungal cell membrane, where it binds to membrane ergosterol, resulting in pore formation and cell lysis (Franzot \& Casadevall, 1997; Gahn et al., 2007).

Several studies support the combination of echinocandins with other antifungal drugs to treat $C$. albicans biofilms (Bink et al., 2011; Kuhn et al., 2002b; Pai, 2009). For example, synergy effects were found for micafungin and fluconazole, voriconazole or liposomal amphotericin B against Candida species (Espinel-Ingroff et al., 2009; Nishi et al., 2009; Olson et al., 2005). The triple combination of liposomal amphotericin B, micafungin and flucytosine (Bink et al., 2011; Pai, 2009), as well as the combination of flucytosine and voriconazole has also been shown to improve the treatment of C. parapsilosis infections (Bink et al., 2011; Pai et al., 2008).

Therefore, combinational therapy has been shown to enhance Candida eradication. For example, it was recently shown that the use of a human antibody fragment, efungumab, in combination with caspofungin enhanced the activity of this agent in vivo (Espinel-Ingroff et al., 2009; Hodgetts et al., 2008). Calcineurin inhibitors FK506 and cyclosporine A also demonstrated a synergistic effect in combination with fluconazole against $C$. albicans biofilms, both in vitro and in vivo studies. The synergism observed was mediated via direct inhibition of $C$. albicans calcineurin, which is known to contribute to fluconazole resistance in biofilms (Bink et al., 2011; Uppluri et al., 2008).

The combination of antibacterial agents with standard concentrations of antifungal agents against $C$. albicans biofilms has also been reported (Bink et al., 2011; Ku et al., 2010; Miceli et al., 2009,). Indeed, Miceli et al (2009) determined that the use of doxycycline at specific concentrations improved the effect of both fluconazole and amphotericin B against $C$. albicans biofilms.

Due to the interesting results of combining antifungals with doxycycline, Ku et al. (2010) determined the activity of other antibacterial agents, including azithromycin, tigecycline and vancomycin against $C$. albicans biofilms. Tigecycline alone was the most active agent against $C$. albicans biofilms, but its combination with amphotericin $\mathrm{B}$, caspofungin and fluconazole was not synergistic and in some cases even inhibited the effect of the antifungal agents (Bink et al., 2011; $\mathrm{Ku}$ et al., 2010). On the other hand, a synergism between fluconazole and minocycline was observed against fluconazole-resistant $C$. albicans clinical isolates. This synergism may have resulted from the enhancement of minocycline on fluconazole penetrating through the biofilm as well as interrupting the calcium balance instead of impacting on the uptake and efflux on fluconazole (Bink et al., 2011; Shi et al., 2010).

Although an interesting approach, it must be noted that the combination of high doses of antibacterial agents with standard concentrations of antifungal agents against
C. albicans biofilms may induce bacterial resistance (Bink et al., 2011).

The combination of different antifungal therapies has not yet demonstrated to result in additional efficacy for the treatment of invasive candidiasis in clinical trials (Van de Veerdonk et al., 2010). In fact, synergism and antagonism are in vitro concepts that are difficult to translate into clinical practice. Consequently, although the evidence of synergism of antifungal combinational therapy in vitro may represent a first step in establishing appropriate antifungal therapy (Bink et al., 2011), additional research is needed regarding the efficacy of these combinations in randomized clinical trials (Espinel-Ingroff et al., 2009).

\section{Natural compounds as agents for antifungal therapy}

Several new therapies are being developed based on medicinal plants, exploring the activity of their extracts, essential oils and fractions against microorganisms (Anibal et al., 2010). The use of natural products aimed the control of fungal diseases is considered as an interesting alternative to synthetic fungicides due to their lower negative impact, reduced cost and adverse reactions to plant preparations compared to modern conventional pharmaceuticals (Doddanna et al., 2013).

Medicinal plants have always played a major role in the development of medicine and public health (Doddanna et al., 2013). At least $80 \%$ of the world population is estimated to be still using traditional medicine, and plants represent a large source of bioactive compounds, which have resulted in the detection of a significant number of therapeutic properties (Anibal et al., 2010; Barros et al., 2010a; Guimarães et al., 2010; Pai et al., 2004; Supreetha et al., 2011). Indeed, approximately $50 \%$ of the new chemical molecules found between 2000 and 2006 have come from natural products (Anibal et al., 2010; Newman \& Cragg, 2007). Finding naturally occurring compounds for use in pharmaceutical applications has become an interesting approach (Barros et al., 2010a; Carneiro et al., 2010; Guimarães et al., 2010).

However, the novel, complex and diverse chemical structures of the compounds obtained from the medicinal plants require a more thorough investigation prior to their use as novel antifungal agents. In this sense, the identification of the medicinal plant extracts active against resistant Candida clinical isolates and showing pathogen selectivity is important from a practical point of view (Anibal et al., 2010).

The antifungal compounds of plants are not well known, but the presence of flavonoids and terpenes and a certain degree of lipophilicity might determine toxicity by the interactions with the membrane constituents and their arrangement (Anibal et al., 2010; Tomás-Barberán et al., 1990). Such compounds can be obtained from wild plants and algae, which are rich in bioactive compounds (Guimarães et al., 2010; Silva et al., 2009), and have been reported to have a variety of biological effects, including anti-oxidant, anti-carcinogenic, anti-inflammatory and antimicrobial activities (Barros et al., 2010b; Tepe et al., 2004).

Many extracts of plants and isolated essential oils have demonstrated to exert biological activity, in vivo and in vitro, which has justified research on the characterization of their 
antimicrobial activity (Agarwal et al., 2010; Anibal et al., 2010; Martínez et al., 1996).

The antimicrobial activity shown by plant oils is mainly due to a number of phenolic and terpenoid compounds, which have antibacterial or antifungal activity (Agarwal et al., 2010).

Agarwal et al. (2010) tested several plants oils, namely, clove (Syzygium aromaticum), tulsi (Ocimum tenuiflorum), ginger grass (Cymbogon martini va. matinii), tea tree (Melaleuca alternifólia), ocimum tenuiflorum (Ocimum tenuiflorum), castor (Ricinus communis), juniper (Juniperus), malkangani (Celastrus paniculatus), coconut (Cocos nucífera), peppermint (Mentha piperita), babchi (Psoralea corylifolia), mahua (Madhuca longifólia), ginger (Zingiber officinale), mustard (Sinapis), rose oil (Rose), jasmine (Jasminum), eucalyptus (Eucalyptus), lavender (Lavandula), linseed (Linum usitatissimum), neem (Azadirachta indica), chamomile (Matricaria recutita), sesame (Sesamum indicum), jyotishmati (Celastrus paniculatus), jojoba (Simmondsia chinensis), walnut (Juglans regia), almond (Prunus dulcis), khus (Chrysopogon zizanioides), wheatgerm (Triticum aestivum), chaulmoogra (Hydnocarpus wightiana) and cade oil (Juniperus oxycedrus). Eighteen of these selected plant oils were found to be effective, with peppermint, eucalyptus, ginger grass and clove oils acting as potent antifungal agents against $C$. albicans with better results than fluconazole. The significant antifungal activity of these oils suggests that they could serve as a source of compounds with therapeutic potential against Candida-related infections (Agarwal et al., 2010).

For its turn, Duarte et al. (2005) observed that the oil of Achillea millefolium, Mikania glomerata and Stachys byzantina have a strong activity against $C$. albicans, while Aloysia triphylla, Anthemis nobilis, Cymbopogon martini, Cyperus articulates, Cyperus rotundus, Lippia alba, Mentha arvensis and Mentha piperita showed moderate activity (Anibal et al., 2010; Duarte et al., 2005).

The antimicrobial nature of the essential oils isolated from several Lamiaceae species has been attributed to the presence of various substances, mainly the phenolic monoterpenes thymol and carvacrol. The individual oil components were tested, and thymol was found to be the most active substance with the widest spectrum, followed by carvacrol, R-terpineol and terpinen-4-ol, whereas $p$-cymene was reported to be the least active (Dorman \& Deans, 2000; Tepe et al., 2004). The results of Tepe et al. (2004) are in agreement with the latter case. However, the most active component was found to be carvacrol, rather than thymol, as already seen in previous studies (Cimanga et al., 2002; Cosentino et al., 1999, Dorman \& Deans, 2000; Tepe et al., 2004).

Anibal et al. (2010) reported some studies where activity against strains of different Candida species were observed using the extracts of Mentha piperita, Arrabidaea chica, Rosmarinus officinalis, Tabebuia avellanedae, Syzygium cumini, Punica granatum, Casearia sylvestris and Arctium lappa. For its turn, Zhang et al. (2006a) observed that the fractions TTS-12 and TTS-15 of Tribulus terrestris had significant antifungal activities against the five yeasts tested: C. albicans, C. glabrata, C. parapsilosis, C. tropicalis and Cryptococcus neoformans (Anibal et al., 2010; Zhang et al., 2006a).
The casbane diterpene fraction extracted from Croton nepataefolius (an aromatic plant native of the Northeast of Brazil extensively used in folk medicine as a sedative and antispasmodic agent) showed antimicrobial activity against some microorganisms tested, namely, C. albicans and C. tropicalis (Carneiro et al., 2010).

Previous studies showed that the ethanolic extracts of some Italian and Ethiopian plants have antimycotic activities against C. albicans (Abdullah et al., 2013), as well as the ethanolic extract of ginger powder. In addition, Silva et al. (2001) investigated ethanol extracts from leaves of Annona crassiflora and A. coriacea, and the fruits of Solanum lycocarpum and $S$. grandiflorum against 52 strains of C. albicans, four strains of $C$. tropicalis and three strains of $C$. krusei clinical isolates. Among these, leaves of A. crassiflora had the greatest antifungal activity, being active against all the microorganisms tested (Silva et al., 2001).

Alves et al. (2014) evaluated the potential antifungal effect of phenolic compounds (gallic acid, catechin, luteolin and quercetin) identified from flowers of the Northeastern Portugal, against Candida planktonic and biofilm cells. In that study, Gallic acid presented the highest antifungal effect against different planktonic Candida species (C. albicans, C. glabrata, C. parapsilosis, C. tropicalis) and catechin showed a similar effect only against $C$. albicans cells. In biofilm evaluation, gallic acid and quercetin demonstrated a slight effect against the different Candida species studied.

Barros et al. (2013b) performed a screening of the antifungal potential of a phenolic extract of Cistus ladanifer from Northeastern Portugal, against different Candida species. The results presented a strong inhibition of $C$. albicans, C. glabrata and C. parapsilosis growth (MIC $<0.05 \mathrm{mg} / \mathrm{mL}$ ), and a moderate inhibition of $C$. tropicalis growth $(\mathrm{MIC}=0.625 \mathrm{mg} / \mathrm{mL} ;$ Barros et al., 2013b). The same authors studied the antifungal potential of a phenolic extract of Castanea sativa, Filipendula ulmaria and Rosa micrantha flowers from Northeastern Portugal, against the mentioned Candida species. Overall, extracts of $C$. sativa, F. ulmaria and $R$. micrantha revealed promising antifungal effects against Candida species, especially in the latter. The stronger effect showed by $R$. micrantha extracts against all Candida species and, particularly its fungicide effects in C. glabrata, might be related to the presence of flavonoids [e.g. (+)-catechin and procyanidin dimers and trimers] that were inexistent in the other samples (Barros et al., 2013a).

However, in spite of the promising results, these are only preliminary studies and the information available regarding active plants against Candida species has not yet resulted in effective formulations for human use. In particular, studies on the effect of these compounds against Candida biofilms have been scarce, and have indicated that high concentrations might be needed to obtain some effect on these structures (Alves et al., 2014).

\section{Immunotherapeutic approaches}

New knowledge on the mechanisms of host defense against Candida infections has led to the development of novel immunotherapeutic approaches to combat these pathogens. Current strategies being developed include vaccination, 
therapeutic antibodies, recombinant cytokines and adoptive transfer of primed immune cells (Table 1; Van de Veerdonk et al., 2010).

\section{Vaccination}

Although vaccination against Candida infections is not yet clinically available, there are many vaccine approaches that seem to be promising, with positive results in animal tests, as those involving the use of diphtheria toxoid CRM197 conjugated with the algal antigen laminarin (Torosantucci et al., 2005; Van de Veerdonk et al., 2010); mannan protein conjugates (Han et al., 1999; Van de Veerdonk et al., 2010); adhesins Als1p and Als3p (Ibrahim et al., 2005, Spellberg et al., 2005, 2006; Van De Veerdonk et al., 2010); and liveattenuated Candida or low virulent CA2 strain (Van de Veerdonk et al., 2010). However, these strategies still need to be assessed for clinical efficacy and safety in humans. An especial challenge is the immunization of immunocompromised patients with Candida infections, since a successful vaccination is dependent on the appropriate host defense mechanisms to provide protection.

The current vaccines can be improved by the use of adjuvants. Recent knowledge into adjuvanticity indicates that it is possible to use adjuvants to shape the kind of adaptive immune response elicited by a vaccine, by inducing different cytokine profiles (Eisenbarth et al., 2008; Mata-Haro et al., 2007; McCluskie \& Krieg, 2006). This can be used to specifically induce optimal defense against a pathogen. For example, the adjuvant should ideally facilitate a strong Th1 [e.g. alum, $\beta$-glucan (Leibundgut-Landmann et al., 2008; Lin et al., 2009; Van de Veerdonk et al., 2010)] and Th17 [e.g. mannans, dectin-2, $\beta$-glucan (Leibundgut-Landmann et al., 2008; Robinson et al., 2009; Van de Veerdonk et al., 2010)] response for disseminated and mucosal candidiasis, respectively.

\section{Antibodies}

Immunotherapy with anti-Candida antibodies is another recent alternative to treat or prevent Candida infections, which is particularly promising as a therapy for immunocompromised patients. These antibodies, induced artificially, have been tested in animal models and patients with candidiasis. Efungumab is an example of a human recombinant antibody that was developed against the fungal-specific heat shock protein 90 (Hsp90; Matthews, 1994). This antibody has been assessed in combination with amphotericin B (Pachl et al., 2006; Van de Veerdonk et al., 2010) and caspofungin (Hodgetts et al., 2008; Van de Veerdonk et al., 2010 ) for the treatment of candidiasis with positive outcomes (Hodgetts et al., 2008; Pachl et al., 2006; Van de Veerdonk et al., 2010).

Other approaches include the use of monoclonal antibodies (mAbs) and immune serum from mice vaccinated with Candida-mannan containing liposomes (Han \& Cutler, 1995; Han et al., 2000; Van de Veerdonk et al., 2010), recombinant anti-mannan antibodies (Van de Veerdonk et al., 2010; Zhang et al., 2006b), protective antibodies induced by synthetic glycopeptide vaccines (Van de Veerdonk et al., 2010; Xin et al., 2008), anti- $\beta$-glucan antibodies induced by

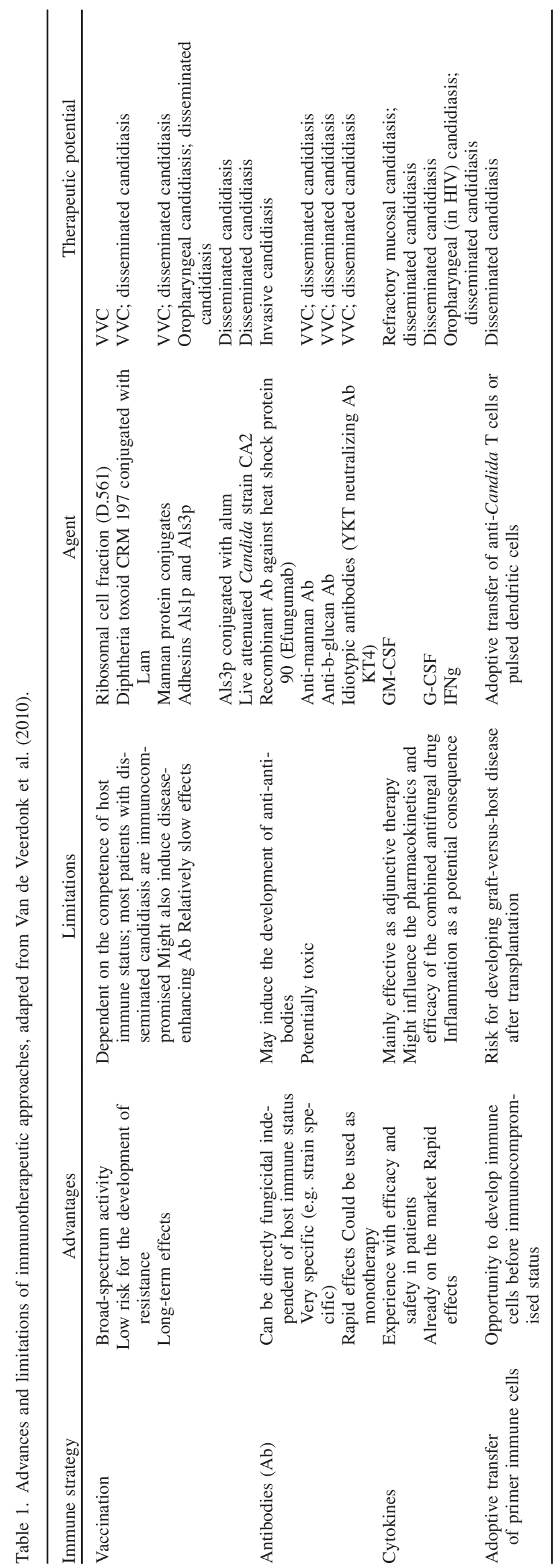


$\beta$-glucanconjugate vaccines (Pietrella et al., 2010; Van de Veerdonk et al., 2010) and idiotypic antibodies directed against KT4 mAbs, which neutralize the effect of the yeast killer toxin YKT (Polonelli et al., 1994; Van de Veerdonk et al., 2010).

\section{Cytokine therapy}

Cytokines can be used to modulate the immunological response during infections. The granulocyte-macrophage colony-stimulating factor (GM-CSF) has been investigated for this purpose. GM-CSF enhances phagocytosis and the release of reactive oxygen species (ROS) by polymorphonuclear leucocytes (PMNs), prolongs the survival of neutrophils by inhibiting the programmed cell death (Brach et al., 1992; Van de Veerdonk et al., 2010), upregulates the expression of dectin-1 on macrophages (Willment et al., 2003) and upregulates chititriosidase promoting fungicidal activity by cleaving the chitin present in the inner cell wall of C. albicans (Van de Veerdonk et al., 2010; Van Eijk et al., 2005). The administration of GM-CSF to both humans and mice significantly reduced the fungal outgrowth (Gaviria et al., 1999; Kullberg et al., 1999; Van de Veerdonk et al., 2010). Furthermore, its use as an adjuvant to antifungal therapy has led to clinical and mycological improvements (Kullberg et al., 2004; Shahar et al., 1999; Van de Veerdonk et al., 2010; Vazquez et al., 1998).

Interferon gamma (IFN $\gamma$ ), produced by $\mathrm{T}$ and NK cells, increases macrophage cytotoxicity and kills intracellular pathogens (Hübel et al., 2002; Van de Veerdonk et al., 2010). IFN $\gamma$ therapy is most effective in patients with granulomatous disease, reducing the incidence of infections, with several studies indicating its benefit for the treatment of Candida infections (Bodasing et al., 2002; Dignani et al., 2005; Van de Veerdonk et al., 2010). However, the particular effectors functions are debatable. Some works indicate an increase of the anti-Candida activity of the macrophages (Baltch et al., 2005; Brummer et al., 1985, 1991; Redmond et al., 1993; Van de Veerdonk et al., 2010), others report no effect on macrophage activity (Marcil et al., 2002; Van de Veerdonk et al., 2010), and some works report an increased capacity of PMNs to kill Candida.

\section{Adoptive transfer of primed immune cells}

Antigen primed dendritic cells (DCs) can be used as another approach for antifungal immunotherapy. For example, by ex vivo priming of dendritic cells with antigens that induce specific cytokine profiles, followed by infusion in the patient (Bacci et al., 2002; Van de Veerdonk et al., 2010), it is possible to angle the adaptive immune response towards antiCandida effector functions (Bozza et al., 2004; Van de Veerdonk et al., 2010). Indeed, it has been shown that DC vaccination induces Th1-dependent antifungal protection in mice that received allogeneic bone marrow transplants (Bozza et al., 2003; Van de Veerdonk et al., 2010). Furthermore, adoptive transfer of anti-Candida $\mathrm{T}$ cells has been proposed as potential immunotherapy in patients with candidiasis after hematopoietic stem cell transplantation (Tramsen et al., 2007; Van de Veerdonk et al., 2010). These $\mathrm{T}$ cells do not appear to be affected by cryopreservation
(Tramsen et al., 2007), so it might be possible to generate anti-Candida $\mathrm{T}$ cells before the patient reaches an immunocompromised status, and adoptively transfer these cells during infection when the patients are immunocompromised (Van de Veerdonk et al., 2010).

\section{Low-level laser therapy}

Laser light has been evaluated, both in vitro and in vivo, as an alternative antimicrobial treatment (Schwarz et al., 2005, 2006; Sennhenn-Kirchner et al., 2009; Soukos et al., 2003). Low-level laser therapy (LLLT) uses low doses of visible light of appropriate wavelength to activate existing biological chromophores in cells, leading to the generation of ROS (Marques et al., 2004; Souza et al., 2010). The LLLT sensitization depends on parameters related to the laser such as wavelength, power density or light intensity that reaches to the tissue and the energy density that is responsible for the desired radiation effect (De Souza et al., 2006; Wilson \& Mia, 1993).

The significant antimicrobial potential of LLLT has been documented in vitro, on diverse microbial species, and in vivo, in the treatment of gingivitis, periodontitis and other oral diseases (Basso et al., 2011; Lino et al., 2011; Moritz et al., 1998; Nussbaum et al., 2003), with most studies focusing on bacteria and few reporting its effect on fungi (De Souza et al., 2006; Donnelly et al., 2007; Ward et al., 1996). The antimicrobial mechanism of LLLT on bacteria seems to be related to thermal effects and photo-disruption (Basso et al., 2011; Maver-Biscanin et al., 2004). LLLT may not cause immediate cell death, but it causes sublethal damages, such as destruction of the cell wall and accumulation of denatured proteins in the bacterial cytoplasm (Basso et al., 2011).

The scarce works using LLLT against fungi involved Candida species, and the LLLT sources used included a near infrared indium gallium arsenide phosphide (InGaAsP) diode laser prototype (LASERTable; $780 \pm 3 \mathrm{~nm}$ wavelength, $0.4 \mathrm{~W}$ power output; Basso et al., 2011), a gallium-aluminum-arsenide (GaAlAs) laser $(660 \mathrm{~nm}$ wavelength, $0.035 \mathrm{~W}$ power output, $0.38 \mathrm{~cm}^{2}$ illuminated area; Souza et al., 2010), an erbium:yttrium-aluminium-garnet (Er:YAG) laser (2940 $\mathrm{nm}$ wavelength) and a diode laser (810 nm wavelength; Sennhenn-Kirchner et al., 2009).

Although some studies have reported the fungicide effect (reductions in $\log \mathrm{CFU} / \mathrm{ml}$ ) of LLLT alone (Maver-Biscanin et al., 2005; Souza et al., 2010), most in vitro works demonstrate that the use of a photosensitizer associated with the laser is very effective against bacteria, yeasts, virus and parasites (De Souza et al., 2006; Sarkar \& Wilson, 1993; Wainwright, 1998; Wilson \& Mia, 1993).

Despite the promising results demonstrated by this new approach for the treatment of Candida infection, much research still need to be done in the area to consolidate the existing findings.

\section{Photodynamic therapy}

Photodynamic therapy (PDT) has been successfully applied to the treatment of malignant neoplasia, particularly among head and neck related tumors. Nowadays, the use of PDT to treat 
other pathologies such as systemic reumatoid arthritis, fungal and bacterial infections has been investigated (De Souza et al., 2006; Teichert et al., 2002; Usacheva et al., 2001; Williams et al., 2003).

PDT is based on the activation of photosensitizers added to cells and microorganisms, by an appropriate wavelength of light in the presence of oxygen, promoting a phototoxic response of the cells, usually via oxidative damage (Dougherty et al., 1998; Mima et al., 2010). Indeed, these photosensitizer products are cytotoxic to the target cell, killing the microorganism by causing disarrangements in the cell wall and DNA damage (Romanova et al., 2003; Souza et al., 2010). This effect leads to alterations in the mitochondrial gradient of ionic concentration, interfering in the respiratory chain, inhibiting or stimulating ATP synthesis and at the same time producing singlet oxygen, toxic to the cells (Bortoletto et al., 2004).

The PDT sensitization depends on the parameters related to the concentration, time of incubation and type of photosensitizer, as well as the physiological state of the microorganisms, time of exposure and energy density of the laser (De Souza et al., 2006; Souza et al., 2010; Teichert et al., 2002; Wilson \& Mia, 1993).

Since most microbial species possess only specific wavelength ranges of endogenous photosensitive components, the use of an exogenous photosensitizer able to absorb light and to initiate the formation of free radicals expands the range of photonics interventions (Souza et al., 2010; Wilson et al., 1992). In this respect, the action of different photosensitizers, mainly phenothiazine dyes, porphyrins and phthalocyanines, has been investigated. Many studies have demonstrated the efficacy of phenothiazine dyes such as methylene blue and toluidine blue in PDT for the reduction of fungi (De Souza et al., 2006; Giroldo et al., 2009; Souza et al., 2010; Teichert et al., 2002). Another substance that can be used as a photosensitizer is malachite green, a cationic dye of the triarylmethane family (which also includes crystal violet).

PDT using the mentioned photosensitizers promotes an effective action in the reduction of the number of Candida cells, especially C. albicans. Indeed, some studies confirm these results (De Souza et al., 2006; Giroldo et al., 2009; Prates et al., 2007; Souza et al., 2010; Wilson \& Mia, 1993). Giroldo et al. (2009) studied the photosensitization of $C$. albicans using the combination of the photosensitizer methylene blue with a diode laser $\left(684 \mathrm{~nm}\right.$ and $\left.28 \mathrm{~J} / \mathrm{cm}^{2}\right)$ and obtained a significant growth decrease. For its turn, de Souza et al. (2006) studied the photosensitization of different Candida species with methylene blue $(0.1 \mathrm{mg} / \mathrm{ml})$ and InGaAlP laser light $\left(685 \mathrm{~nm}\right.$ and $\left.28 \mathrm{~J} / \mathrm{cm}^{2}\right)$ and found a reduction in the numbers of $\mathrm{CFU} / \mathrm{ml}$ of $91.6 \%$ of $C$. krusei, $88.6 \%$ of C. albicans, $84.8 \%$ of C. dubliniensis and $82.3 \%$ of C. tropicalis. In a study by Wilson \& Mia (1993) a reduction in the numbers of $\mathrm{CFU} / \mathrm{ml}$ of $77 \%$ for $C$. albicans, $65 \%$ for C. tropicalis, $63 \%$ for C. stellatoidea and $40 \%$ for $C$. kefyr was reported when these species were subjected to toluidine blue combined with helium-neon (He-Ne) laser light $\left(632.8 \mathrm{~nm}\right.$ and $\left.66.36 \mathrm{~J} / \mathrm{cm}^{2}\right)$. Other study with C. albicans sensitized in vitro by toluidine blue, thionin and crystal violet associated with $\mathrm{He}-\mathrm{Ne}$ laser, showed a higher microbial reduction with toluidine blue (Wilson \& Mia, 1993). This photosensitizer was also the most effective in a study by Souza et al. (2010) against different Candida species, where methylene blue, malachite green and low-power laser irradiation alone were also tested.

It is important to mention that divergent results have been obtained on studies concerning the application of photosensitizers alone in the absence of laser irradiation. While some show no significant difference when compared with the control groups, others demonstrate the presence of antifungal activity (Calzavara-Pinton et al., 2005; Souza et al., 2010; Usacheva et al., 2001; Wainwright \& Crossley, 2002). These divergences reported in the literature might be due to the lack of pre-defined parameters for the use of PDT, a fact that impairs a reliable comparison between the results obtained in different studies.

In consequence of the use of non-specific oxidizing agents, organisms resistant to conventional antifungal agents may be successfully killed by PDT and the development of resistance to this therapy seems unlikely, making this a very promising therapy (Mima et al., 2010). However, evidently, the knowledge about the application of PDT and also LLLT to Candida species is even scarcer and demands for more and reliable studies in the area.

\section{Concluding remarks}

Candida infections account for a high burden of morbidity and mortality. Prolonged usage of antifungal agents to treat infections caused by Candida species has led to the emergence of resistance to conventional drugs. Considering this, new therapeutic approaches are urgently needed to improve the outcome of the patients, as the currently available treatment options have not reduced the mortality and morbidity associated with Candida infections over the recent years.

Possible solutions to improve the efficacy of the treatment would be the use of combined antifungal drugs and the exploration of alternatives compounds as antifungal agents (extracts of plants and isolated essential oils). One of the most promissory sources for the research of new agents is actually found in plants, which have compounds with antimicrobial properties that are only now beginning to be studied. The investigation of these active principles may be a potential area that must be explored.

Other solution would be the use of immunotherapy, which aims at improving host defense against Candida. The increase in understanding the mechanisms that underlie the pathogenesis of Candida infection could bring closer the development of efficient and feasible immunotherapeutic strategies.

Another approach discussed in the present review relates to the use of PDT and LLLT. Although, the significant fungicide potential of LLLT and PDT has been documented and proved in several studies it is evident that the knowledge about the application of these therapies to Candida species is even scarcer and demands for more and reliable studies in the area.

Therefore, although several methodologies have been developing in the last years to treat Candida infections, there is still much to do. 


\section{Declaration of interest}

The authors declare that they have no conflicts of interest. The authors thank the FCT Strategic Project PEst-OE/EQB/ LA0023/2013 and the Project "BioHealth - Biotechnology and Bioengineering approaches to improve health quality", Ref. NORTE-07-0124-FEDER-000027, co-funded by the Programa Operacional Regional do Norte (ON.2 - O Novo Norte), QREN, FEDER. The authors also acknowledge the project "Consolidating Research Expertise and Resources on Cellular and Molecular Biotechnology at CEB/IBB', Ref. FCOMP-01-0124-FEDER-027462 and the projects PTDC/ EBB-EBI/120495/2010 and PTDC/SAU-MIC/119069/2010, from the Programa Operacional, Fatores de competitividade COMPETE and by national funds through FCT.

\section{References}

Abdullah K, Soliman M, Mohamed M. (2013). Susceptibility of Candida albicans clinical isolates to some plant extracts in Saudi Arabia. ZUMJ 19:294-9.

Agarwal V, Lal P, Pruthi V. (2010). Effect of plant oils on Candida albicans. J Microbiol Immunol Infect 43:447-51.

Almirante B, Rodriguez D, Cuenca-Estrella M, et al. (2006). Epidemiology, risk factors, and prognosis of Candida parapsilosis bloodstream infections: case-control population-based surveillance study of patients in Barcelona, Spain, from 2002 to 2003. J Clin Microbiol 44:1681-5.

Alves C, Ferreira I, Barros L, et al. (2014). Antifungal activity of phenolic compounds identified in flowers from the North Eastern Portugal against Candida species biofilms. Future Microbiol 9:139-46.

Andes D. (2003). In vivo pharmacodynamics of antifungal drugs in treatment of candidiasis. Antimicrob Agents Chemother 47:1179-86.

Anibal PC, Sardi JDCO, Peixoto ITA, et al. (2010). Conventional and alternative antifungal therapies to oral candidiasis. Braz J Microbiol 41:824-31.

Antoniadou A, Torres HA, Lewis RE, et al. (2003). Candidemia in a tertiary care cancer center: in vitro susceptibility and its association with outcome of initial antifungal therapy. Medicine (Baltimore) 82: 309-21.

Arendrup MC, Fuursted K, Gahrn-Hansen B, et al. (2005). Seminational surveillance of fungemia in Denmark: notably high rates of fungemia and numbers of isolates with reduced azole susceptibility. J Clin Microbiol 43:4434-40.

Arendrup MC, Fuursted K, Gahrn-Hansen B, et al. (2008). Semi-national surveillance of fungaemia in Denmark 2004-2006: increasing incidence of fungaemia and numbers of isolates with reduced azole susceptibility. Clin Microbiol Infect 14:487-94.

Bacci A, Montagnoli C, Perruccio K, et al. (2002). Dendritic cells pulsed with fungal RNA induce protective immunity to Candida albicans in hematopoietic transplantation. J Immunol 168:2904-13.

Baltch AL, Bopp LH, Smith RP, et al. (2005). Effects of voriconazole, granulocyte-macrophage colony-stimulating factor, and interferon $\gamma$ on intracellular fluconazole-resistant Candida glabrata and Candida krusei in human monocyte-derived macrophages. Diagn Microbiol Infect Dis 52:299-304.

Baltch AL, Bopp LH, Smith RP, et al. (2008). Anticandidal effects of voriconazole and caspofungin, singly and in combination, against Candida glabrata, extracellularly and intracellularly in granulocytemacrophage colony stimulating factor (GM-CSF)-activated human monocytes. J Antimicrob Chemother 62:1285-90.

Barros L, Alves CT, Duenas M, et al. (2013a). Characterization of phenolic compounds in wild medicinal flowers from Portugal by HPLC-DAD-ESI/MS and evaluation of antifungal properties. Ind Crops Prod 44:104-10.

Barros L, Carvalho AM, Ferreira ICFR. (2010a). Leaves, flowers, immature fruits and leafy flowered stems of Malva sylvestris: a comparative study of the nutraceutical potential and composition. Food Chem Toxicol 48:1466-72.

Barros L, Duenas M, Alves CT, et al. (2013b). Antifungal activity and detailed chemical characterization of Cistus ladanifer phenolic extracts. Ind Crops Prod 41:41-5.
Barros L, Oliveira S, Carvalho AM, Ferreira ICFR. (2010b). In vitro antioxidant properties and characterization in nutrients and phytochemicals of six medicinal plants from the Portuguese folk medicine. Ind Crops Prod 32:572-9.

Barwicz J, Dumont I, Ouellet C, Gruda I. (1998). Amphotericin B toxicity as related to the formation of oxidatively modified lowdensity lipoproteins. Biospectroscopy 4:135-44.

Bassetti M, Trecarichi EM, Righi E, et al. (2007). Incidence, risk factors, and predictors of outcome of candidemia. Survey in 2 Italian university hospitals. Diagn Microbiol Infec Dis 58:325-31.

Basso FG, Oliveira CF, Fontana A, et al. (2011). In vitro effect of lowlevel laser therapy on typical oral microbial biofilms. Braz Dent J 22: 502-10.

Bink A, Pellens K, Cammue BPA, Thevissen K. (2011). Anti-biofilm strategies: how to eradicate Candida biofilms? Open Mycol J 5:29-38.

Blot SI, Vandewoude KH, Hoste EA, Colardyn FA. (2002). Effects of nosocomial candidemia on outcomes of critically ill patients. Am J Med 113:480-5.

Blumber HM, Jarvis WR, Soucie JM, et al. (2001). Risk factors for candidal bloodstream infections in surgical intensive care unit patients: the NEMIS prospective multicenter study. Clin Infect Dis 33:177-86.

Bodasing N, Seaton RA, Shankland GS, Pithie A. (2002). Gammainterferon treatment for resistant oropharyngeal candidiasis in an HIVpositive patient. J Antimicrob Chemother 50:765-6.

Bortoletto R, Silva NS, Zângaro RA, et al. (2004). Mitochondrial membrane potential after low-power laser irradiation. Lasers Med Sci 18:204-6.

Bossche HV, Willemsens G, Marichal P. (1987). Anti-Candida drugs the biochemical basis for their activity. Crit Rev Microb 15:57-72.

Bozza S, Montagnoli C, Gaziano R, et al. (2004). Dendritic cell-based vaccination against opportunistic fungi. Vaccine 22:857-64.

Bozza S, Perruccio K, Montagnoli C, et al. (2003). A dendritic cell vaccine against invasive aspergillosis in allogeneic hematopoietic transplantation. Blood 102:3807-14.

Brach M, Devos S, Gruss H, Herrmann F. (1992). Prolongation of survival of human polymorphonuclear neutrophils by granulocytemacrophage colony-stimulating factor is caused by inhibition of programmed cell death. Blood 80:2920-4.

Brajtburg J, Powderly WG, Kobayashi GS, Medoff G. (1990). Amphotericin B: current understanding of mechanisms of action. Antimicrob Agents Chemother 34:183-8.

Brammer KW, Farrow PR, Faulkner JK. (1990). Pharmacokinetics and tissue penetration of fluconazole in humans. Rev Infect Dis 12: S318-26.

Brummer E, Hanson LH, Stevens DA. (1991). Kinetics and requirements for activation of macrophages for fungicidal activity: effect of protein synthesis inhibitors and immunosuppressants on activation and fungicidal mechanism. Cell Immunol 132:236-45.

Brummer E, Morrison CJ, Stevens DA. (1985). Recombinant and natural gamma-interferon activation of macrophages in vitro: different dose requirements for induction of killing activity against phagocytizable and nonphagocytizable fungi. Infect Immun 49:724-30.

Caillot D, Reny G, Solary E, et al. (1994). A controlled trial of the tolerance of amphotericin B infused in dextrose or in Intralipid in patients with haematological malignancies. J Antimicrob Chemother 33:603-13.

Calzavara-Pinton PG, Venturini M, Sala R. (2005). A comprehensive overview of photodynamic therapy in the treatment of superficial fungal infections of the skin. J Photochem Photobiol B 78:1-6.

Carneiro VA, Santos HSD, Arruda FVS, et al. (2010). Casbane diterpene as a promising natural antimicrobial agent against biofilm-associated infections. Molecules 16:190-201.

Chandra J, Kuhn DM, Mukherjee PK, et al. (2001). Biofilm formation by the fungal pathogen Candida albicans: development, architecture, and drug resistance. J Bacteriol 183:5385-94.

Cimanga K, Kambu K, Tona L, et al. (2002). Correlation between chemical composition and antibacterial activity of essential oils of some aromatic medicinal plants growing in the Democratic Republic of Congo. J Ethnopharmacol 79:213-20.

Colombo AL, Nucci M, Salomão R, et al. (1999). High rate of nonalbicans candidemia in Brazilian tertiary care hospitals. Diagnos Microbiol Infect Dis 34:281-6.

Cosentino S, Tuberoso CIG, Pisano B, et al. (1999). In-vitro antimicrobial activity and chemical composition of Sardinian Thymus essential oils. Lett Appl Microbiol 29:130-5. 
De Souza SC, Junqueira JC, Balducci I, et al. (2006). Photosensitization of different Candida species by low power laser light. J Photochem Photobiol B 83:34-8.

Deray G. (2002). Amphotericin B nephrotoxicity. J Antimicrob Chemother 49:37-41.

Diekema DJ, Messer SA, Brueggemann AB, et al. (2002). Epidemiology of Candidemia: 3-year results from the emerging infections and the epidemiology of Iowa organisms study. J Clin Microbiol 40: 1298-302.

Dignani MC, Rex JH, Chan KW, et al. (2005). Immunomodulation with interferon-gamma and colony-stimulating factors for refractory fungal infections in patients with leukemia. Cancer 104:199-204.

Doddanna SJ, Patel S, Sundarrao MA, Veerabhadrappa RS. (2013). Antimicrobial activity of plant extracts on Candida albicans: an in vitro study. Indian J Dent Res 24:401-5.

Donnelly RF, Mccarron PA, Tunney MM, David Woolfson A. (2007). Potential of photodynamic therapy in treatment of fungal infections of the mouth. Design and characterisation of a mucoadhesive patch containing toluidine blue O. J Photochem Photobiol B 86:59-69.

Dorman HJD, Deans SG. (2000). Antimicrobial agents from plants: antibacterial activity of plant volatile oils. J Appl Microbiol 88: 308-16.

Dougherty TJ, Gomer CJ, Henderson BW, et al. (1998). Photodynamic therapy. J Natl Cancer Inst 90:889-905.

Douglas CM. (2001). Fungal beta(1,3)-D-glucan synthesis. Med Mycol 39:55-66.

Duarte MCT, Figueira GM, Sartoratto A, et al. (2005). Anti-Candida activity of Brazilian medicinal plants. J Ethnopharmacol 97:305-11.

Dupont BF, Lortholary O, Ostrosky-Zeichner L, et al. (2009). Treatment of candidemia and invasive candidiasis in the intensive care unit: post hoc analysis of a randomized, controlled trial comparing micafungin and liposomal amphotericin B. Crit Care 13:159.

Eisenbarth SC, Colegio OR, O/'Connor W, et al. (2008). Crucial role for the Nalp3 inflammasome in the immunostimulatory properties of aluminium adjuvants. Nature 453:1122-6.

Enoch DA, Ludlam HÁ, Brown NM. (2006). Invasive fungal infections: a review of epidemiology and management options. J Med Microbiol 55:809-18.

Espinel-Ingroff A, Canton E, Martin ME, Pemán J. (2009). Pharmacotherapy of Candida infections with echinocandins. Clin Med Insights Ther 1:889-97.

Fanning S, Mitchell AP. (2012). Fungal biofilms. PLoS Pathogens 8:1-4.

Francis P, Walsh TJ. (1992). Evolving role of flucytosine in immunocompromised patients: new insights into safety, pharmacokinetics, and antifungal therapy. Clin Infect Dis 15:1003-18.

Franzot SP, Casadevall A. (1997). Pneumocandin L-743,872 enhances the activities of amphotericin B and fluconazole against Cryptococcus neoformans ins vitro. Antimicrob Agents Chemother 41:331-6.

Gahn B, Schub N, Repp R, Gramatzki M. (2007). Triple antifungal therapy for severe systemic candidiasis allowed performance of allogeneic stem cell transplantation. Eur J Med Res 12:337-40.

Gaviria JM, Van Burik J-AH, Dale DC, et al. (1999). Modulation of neutrophil-mediated activity against the pseudohyphal form of Candida albicans by granulocyte colony-stimulating factor (G-CSF) administered in vivo. J Infect Dis 179:1301-4.

Giroldo L, Felipe M, Oliveira M, et al. (2009). Photodynamic antimicrobial chemotherapy (PACT) with methylene blue increases membrane permeability in Candida albicans. Lasers Med Sci 24: $109-12$.

González JA, García-Barriuso M, Amich F. (2010). Ethnobotanical study of medicinal plants traditionally used in the Arribes del Duero, western Spain. J Ethnopharmacol 131:343-55.

Gudlaugsson O, Gillespie S, Lee K, et al. (2003). Attributable mortality of nosocomial candidemia, revisited. Clin Infect Dis 37:1172-7.

Guery B, Arendrup M, Auzinger G, et al. (2009). Management of invasive candidiasis and candidemia in adult non-neutropenic intensive care unit patients: Part I. Epidemiology and diagnosis. Intens Care Med 35:55-62.

Guimarães R, Barros L, Carvalho AM, Ferreira ICFR. (2010). Studies on chemical constituents and bioactivity of Rosa micrantha: an alternative antioxidants source for food, pharmaceutical, or cosmetic applications. J Agric Food Chem 58:6277-84.

Han Y, Cutler JE. (1995). Antibody response that protects against disseminated candidiasis. Infect Immun 63:2714-19.
Han Y, Riesselman MH, Cutler JE. (2000). Protection against Candidiasis by an immunoglobulin G3 (IgG3) monoclonal antibody specific for the same mannotriose as an $\operatorname{IgM}$ protective antibody. Infect Immun 68:1649-54.

Han Y, Ulrich MA, Cuttler JE. (1999). Candida albicans mannan extract - protein conjugates induce a protective immune response against experimental Candidiasis. J Infect Dis 179:1477-84.

Henry KW, Nickels JT, Edlind TD. (2000). Upregulation of ERG genes in Candida species by azoles and other sterol biosynthesis inhibitors. Antimicrob Agents Chemother 44:2693-700.

Hodgetts S, Nooney L, Al-Akeel R, et al. (2008). Efungumab and caspofungin: pre-clinical data supporting synergy. J Antimicrob Chemother 61:1132-9.

Hübel K, Dale DC, Liles WC. (2002). Therapeutic use of cytokines to modulate phagocyte function for the treatment of infectious diseases: current status of granulocyte colony-stimulating factor, granulocytemacrophage colony-stimulating factor, macrophage colony-stimulating factor, and interferon- $\gamma$. J Infect Dis 185:1490-501.

Ibrahim AS, Spellberg BJ, Avenissian V, et al. (2005). Vaccination with recombinant $\mathrm{N}$-terminal domain of Als1p improves survival during murine disseminated Candidiasis by enhancing cell-mediated, not humoral, immunity. Infect Immun 73:999-1005.

Ibrahim EH, Sherman G, Ward S, et al. (2000). The influence of inadequate antimicrobial treatment of bloodstream infections on patient outcomes in the icu setting. Chest J 118:146-55.

Jabra-Rizk MA, Falkler WA, Meiller TF. (2004). Fungal biofilms and drug resistance. Emerg Infect Dis 10:14-19.

Baran Jr J, Muckatira B, Khatib R. (2001). Candidemia before and during the fluconazole era: prevalence, type of species and approach to treatment in a tertiary care community hospital. Scand J Infect Dis 33:137-9.

Katragkou A, Chatzimoschou A, Simitsopoulon M, et al. (2008). Differential activities of newer antifungal agents against Candida albicans and Candida parapsilosis biofilms. Antimicrob Agents Chemother 52:357-60.

Kojic EM, Darqouiche RO. (2004). Candida infections of medical devices. Clin Microbiol Rev 17:255-67.

Krcméry Jr V, Kovacicová G. (2000). Longitudinal 10-year prospective survey of fungaemia in Slovak Republic: trends in etiology in 310 episodes. Diagn Microbiol Infect Dis 36:7-11.

Ku TSN, Palanisamy SKA, Lee SA. (2010). Susceptibility of Candida albicans biofilms to azithromycin, tigecycline and vancomycin and the interaction between tigecycline and antifungals. Int $\mathbf{J}$ Antimicrob Agents 36:441-6.

Kuhn DM, Chandra J, Mukherjee PK, Ghannoum MA. (2002a). Comparison of biofilms formed by Candida albicans and Candida parapsilosis on bioprosthetic surfaces. Infect Immun 70:878-88.

Kuhn DM, George T, Chandra J, et al. (2002b). Antifungal susceptibility of Candida biofilms: unique efficacy of amphotericin B lipid formulations and echinocandins. Antimicrob Agents Chemother 46: 1773-80.

Kullberg BJ, Oude Lashof AM, Netea MG. (2004). Design of efficacy trials of cytokines in combination with antifungal drugs. Clin Infect Dis 39:S218-23.

Kullberg BJ, Netea MG, Vonk AG, Vand Der Mer JW. (1999). Modulation of neutrophil function in host defense against disseminated Candida albicans infection in mice. FEMS Immunol Med Microbiol 26:299-307.

Kullberg BJ, Sobel JD, Ruhnke M, et al. (2005). Voriconazole versus a regimen of amphotericin B followed by fluconazole for candidaemia in non-neutropenic patients: a randomised non-inferiority trial. Lancet 366:1435-42.

Kullberg BJ, Verweij PE, Akova M, et al. (2011). European expert opinion on the management of invasive candidiasis in adults. Clin Microbiol Infect 17:1-12.

Kyle AA, Dahl MV. (2004). Topical therapy for fungal infections. Am J Clin Dermatol 5:443-51.

Leibundgut-Landmann S, Osorio F, Brown GD, et al. (2008). Stimulation of dendritic cells via the dectin-1/Syk pathway allows priming of cytotoxic T-cell responses. Blood 112:4971-80.

Lewis RE, Kontoyiannis DP. (2001). Rationale for combination antifungal therapy. Pharmacotherapy 21:149S-64S.

Lin L, Ibrahim AS, Xu X, et al. (2009). Th1-Th17 cells mediate protective adaptive immunity against Staphylococcus aureus and Candida albicans infection in mice. PLoS Phatogens 5:e1000703. 
Lino MD, Carvalho FB, Oliveira LR, et al. (2011). Laser phototherapy as a treatment for radiotherapy-induced oral mucositis. Braz Dent J 22: $162-5$.

Luber AD, Maa L, Lam M, Guglielmo BJ. (1999). Risk factors for amphotericin B- induced nephrotoxicity. J Antimicrob Chemother 43: 267-71.

Macphall GLP, Taylor GD, Buchanan-Chell M, et al. (2002). Epidemiology, treatment and outcome of candidemia: a five-year review at three Canadian hospitals. Mycoses 45:141-5.

Marchetti O, Bille J, Fluckiger U, et al. (2004). Epidemiology of Candidemia in Swiss Tertiary Care Hospitals: Secular Trends, 19912000. Clin Infect Dis 38:311-20.

Marcil A, Harcus D, Thomas DY, Whiteway M. (2002). Candida albicans killing by RAW 264.7 mouse macrophage cells: effects of Candida genotype, infection ratios, and gamma interferon treatment. Infect Immun 70:6319-29.

Marques MM, Pereira AN, Fujihara NA, et al. (2004). Effect of lowpower laser irradiation on protein synthesis and ultrastructure of human gingival fibroblasts. Lasers Surg Med 34:260-5.

Martínez MJ, Betancourt J, Alonso-González N, Jauregui A. (1996). Screening of some Cuban medicinal plants for antimicrobial activity. J Ethnopharmacol 52:171-4.

Mata-Haro V, Cekic C, Martin M, et al. (2007). The vaccine adjuvant monophosphoryl lipid a as a TRIF-biased agonist of TLR4. Science 316:1628-32.

Matthews RC. (1994). Pathogenicity determinants of Candida albicans: potential targets for immunotherapy? Microbiology 140:1505-11.

Maver-Biscanin M, Mravak-Stipetic M, Jerolimov V. (2005). Effect of low-level laser therapy on Candida albicans growth in patients with denture stomatitis. Photomed Laser Surg 23:328-32.

Maver-Biscanin M, Mravak-Stipetic M, Jerolimov V, Biscanin A. (2004). Fungicidal effect of diode laser irradiation in patients with denture stomatitis. Lasers Surg Med 35:259-62.

McCluskie MJ, Krieg AM. (2006). Enhancement of infectious disease vaccines through TLR9-dependent recognition of $\mathrm{CpG}$ DNA. In: Pulendran B, Ahmed R, eds. From innate immunity to immunological memory. Berlin/Heidelberg: Springer.

Miceli MH, Bernardo SM, Lee SA. (2009). In vitro analyses of the combination of high-dose doxycycline and antifungal agents against Candida albicans biofilms. Int J Antimicrob Agents 34:326-32.

Michalopoulos AS, Geroulanos S, Menitzelopoulos SD. (2003). Determinants of candidemia and candidemia-related death in cardiothoracic icu patients. Chest J 124:2244-55.

Mima EGDO, Pavarina AC, Dovigo LN, et al. (2010). Susceptibility of Candida albicans to photodynamic therapy in a murine model of oral candidosis. Oral Surg Oral Med Oral Pathol Oral Radiol Endod 109: 392-401.

Mora-Duarte J, Betts R, Rotstein C, et al. (2002). Comparison of Caspofungin and amphotericin B for invasive candidiasis. N Engl J Med 347:2020-9.

Moritz A, Schoop U, Goharkhay K, et al. (1998). Treatment of periodontal pockets with a diode laser. Lasers Surg Med 22:302-11.

Morrell M, Fraser VJ, Kollef MH. (2005). Delaying the empiric treatment of Candida bloodstream infection until positive blood culture results are obtained: a potential risk factor for hospital mortality. Antimicrob Agents Chemother 49:3640-5.

Morrison VA. (2006). Echinocandin antifungals: review and update. Expert Rev Anti Infect Ther 4:325-42.

Munoz P, Burillo A, Bouza E. (2000). Criteria used when initiating antifungal therapy against Candida spp. in the intensive care unit. Int J Antimicrob Agents 15:83-90.

Newman DJ, Cragg GM. (2007). Natural products as sources of new drugs over the last 25 rears. J Nat Prod 70:461-77.

Nishi I, Sunada A, Toyokawa M, et al. (2009). In vitro antifungal combination effects of micafungin with fluconazole, voriconazole, amphotericin B, and flucytosine against clinical isolates of Candida species. J Infect Chemother 15:1-5.

Nussbaum EL, Lilge L, Mazzulli T. (2003). Effects of low-level laser therapy (LLLT) of $810 \mathrm{~nm}$ upon in vitro growth of bacteria: relevance of irradiance and radiant exposure. J Clin Laser Med Surg 21:283-90.

Olson JA, Adler-Moore JP, Smith PJ, Proffitt RT. (2005). Treatment of Candida glabrata infection in immunosuppressed mice by using a combination of liposomal amphotericin B with caspofungin or micafungin. Antimicrob Agents Chemother 49:4895-902.
Onishi J, Meinz M, Thompson J, et al. (2000). Discovery of novel antifungal (1,3)- $\beta$-d-glucan synthase inhibitors. Antimicrob Agents Chemother 44:368-77.

Onyewu C, Heitman J. (2007). Unique applications of novel antifungal drug combinations. Anti Infect Agents Med Chem 6:3-15.

Pachl J, Svoboda P, Jacobs F, et al. (2006). A randomized, blinded, multicenter trial of lipid-associated amphotericin $\mathrm{B}$ alone versus in combination with an antibody-based inhibitor of heat shock protein 90 in patients with invasive candidiasis. Clin Infect Dis 42:1404-13.

Pai MP. (2009). Antifungal combinations against simulated Candida albicans endocardial vegetations down-pointing small open triangle. Antimicrob Agents Chemother 53:2629-31.

Pai MP, Samples ML, Mercier R-C, Splide MN. (2008). Activities and ultrastructural effects of antifungal combinations against simulated Candida endocardial vegetations. Antimicrob Agents Chemother 52: 2367-76.

Pai MR, Acharya LD, Udupa N. (2004). Evaluation of antiplaque activity of Azadirachta indica leaf extract gel - a 6-week clinical study. J Ethnopharmacol 90:99-103.

Pappas PG, Rex JH, Lee J, et al. (2003). A prospective observational study of Candidemia: epidemiology, therapy, and influences on mortality in hospitalized adult and pediatric patients. Clin Infect Dis 37:634-43.

Pappas PG, Rex JH, Sobel JD, et al. (2004). Guidelines for Treatment of Candidiasis. Clin Infect Dis 38:161-89.

Pasqualotto AC, Howard SJ, Moore CB, Denning DW. (2007). Flucytosine therapeutic monitoring: 15 years experience from the UK. J Antimicrob Chemother 59:791-3.

Pfaller MA, Boyken L, Hollis RJ, et al. (2008). In vitro susceptibility of invasive isolates of Candida spp. to anidulafungin, caspofungin, and micafungin: six years of global surveillance. J Clin Microbiol 46: $150-6$.

Pfaller MA, Jones RN, Messer SA, et al. (1998). National surveillance of nosocomial blood stream infection due to species of Candida other than Candida albicans: frequency of occurrence and antifungal susceptibility in the SCOPE program. Diagn Microbiol Infect Dis 30: 121-9.

Pietrella D, Rachini A, Torosantucci A, et al. (2010). A $\beta$-glucanconjugate vaccine and anti- $\beta$-glucan antibodies are effective against murine vaginal candidiasis as assessed by a novel in vivo imaging technique. Vaccine 28:1717-25.

Polonelli L, De Bernardis F, Conti S, et al. (1994). Idiotypic intravaginal vaccination to protect against candidal vaginitis by secretory, yeast killer toxin-like anti-idiotypic antibodies. J Immunol 152:3175-82.

Prates RA, Yamada Jr AM, Suzuki LC, et al. (2007). Bactericidal effect of malachite green and red laser on Actinobacillus actinomycetemcomitans. J Photochem Photobiol B 86:70-6.

Redmond HP, Shou J, Gallagher HJ, et al. (1993). Macrophagedependent candidacidal mechanisms in the murine system. Comparison of murine Kupffer cell and peritoneal macrophage candidacidal mechanisms. J Immunol 150:3427-33.

Robinson MJ, Osorio F, Rosas M, et al. (2009). Dectin-2 is a Sykcoupled pattern recognition receptor crucial for Th17 responses to fungal infection. J Exp Med 206:2037-51.

Rocco TR, Reinert SE, Simms H. (2000). Effects of fluconazole administration in critically ill patients: analysis of bacterial and fungal resistance. Arch Surg 135:160-5.

Romanova NA, Brovko LY, Moore L, et al. (2003). Assessment of photodynamic destruction of Escherichia coli $\mathrm{O} 157: \mathrm{H} 7$ and Listeria monocytogenes by using ATP bioluminescence. Appl Environ Microbiol 69:6393-8.

Ruhnke M. (2006). Epidemiology of Candida albicans infections and role of non-Candida albicans yeasts. Curr Drug Targets 7:495-504.

Ruhnke M, Rickerts V, Cornely OA, et al. (2011). Diagnosis and therapy of Candida infections: joint recommendations of the German Speaking Mycological Society and the Paul-Ehrlich-Society for Chemotherapy. Mycoses 54:279-310.

Rüping MJ, Vehreschild JJ, Cornely OA. (2008). Patients at high risk of invasive fungal infections: when and how to treat. Drugs 68: 1941-62.

Sanglard D, Ischer F, Marchetti O, et al. (2003). Calcineurin A of Candida albicans: involvement in antifungal tolerance, cell morphogenesis and virulence. Mol Microbiol 48:959-76.

Saravolatz LD, Deresinski SC, Stevens DA. (2003). Caspofungin. Clin Infect Dis 36:1445-57. 
Sarkar S, Wilson M. (1993). Lethal photosensitization of bacteria in subgingival plaque from patients with chronic periodontitis. J Periodontal Res 28:204-10.

Sawaya BP, Briggs JP, Schnermann J. (1995). Amphotericin B nephrotoxicity: the adverse consequences of altered membrane properties. J Am Soc Nephrol 6:154-64.

Schwarz F, Bieling K, Bonsmann M, et al. (2006). Nonsurgical treatment of moderate and advanced periimplantitis lesions: a controlled clinical study. Clin Oral Investig 10:279-88.

Schwarz F, Sculean A, Romanos G, et al. (2005). Influence of different treatment approaches on the removal of early plaque biofilms and the viability of SAOS2 osteoblasts grown on titanium implants. Clin Oral Investig 9:111-17.

Sendid B, Cotteau A, Francois N, et al. (2006). Candidaemia and antifungal therapy in a French University Hospital: rough trends over a decade and possible links. BMC Infect Dis 6:80.

Sennhenn-Kirchner S, Schwarz P, Schliephake H, et al. (2009). Decontamination efficacy of erbium:yttrium-aluminium-garnet and diode laser light on oral Candida albicans isolates of a 5-day in vitro biofilm model. Lasers Med Sci 24:313-20.

Shahar E, Krivoy N, Pollack S. (1999). Effective acute desensitization for immediate-type hypersensitivity to human granulocyte-monocyte colony stimulating factor. Ann Allergy Asthma Immunol 83:543-6.

Shi W, Chen Z, Chen X, et al. (2010). The combination of minocycline and fluconazole causes synergistic growth inhibition against Candida albicans: an in vitro interaction of antifungal and antibacterial agents. FEMS Yeast Res 10:885-93.

Silva MV, Costa TR, Costa MR, et al. (2001). Growth inhibition effect of Brazilian Cerrado plant extracts on Candida species. Pharm Biol 39:138-41.

Silva S, Henriques M, Martins A, et al. (2009). Biofilms of non-Candida albicans Candida species: quantification, structure and matrix composition. Med Mycol 47:681-9.

Sims CR, Ostrosky-Zeichner L, Rex JH. (2005). Invasive Candidiasis in immunocompromised hospitalized patients. Arch Med Res 36: $660-71$.

Soukos NS, Mulholland SE, Socransky SS, Doukas AG. (2003). Photodestruction of human dental plaque bacteria: enhancement of the photodynamic effect by photomechanical waves in an oral biofilm model. Lasers Surg Med 33:161-8.

Souza R, Junqueira J, Rossoni R, et al. (2010). Comparison of the photodynamic fungicidal efficacy of methylene blue, toluidine blue, malachite green and low-power laser irradiation alone against Candida albicans. Lasers Med Sci 25:385-9.

Spellberg BJ, Ibrahim AS, Avanesian V, et al. (2006). Efficacy of the Anti-Candida rAls3p-N or rAls1p-N vaccines against disseminated and mucosal Candidiasis. J Infect Dis 194:256-60.

Spellberg BJ, Ibrahim AS, Avanesian V, et al. (2005). The anti-Candida albicans vaccine composed of the recombinant $\mathrm{N}$ terminus of Als $1 \mathrm{p}$ reduces fungal burden and improves survival in both immunocompetent and immunocompromised mice. Infect Immun 73:6191-3.

Supreetha S, Sharadadevi M, Sequeira PS, et al. (2011). Antifungal activity of ginger extract on Candida Albicans: an in-vitro study. J Dent Sci Res 2:1-5.

Teichert MC, Jones JW, Usacheva MN, Biel MA. (2002). Treatment of oral candidiasis with methylene blue-mediated photodynamic therapy in an immunodeficient murine model. Oral Surg Oral Med Oral Pathol Oral Radiol Endontol 93:155-60.

Tepe B, Daferera D, Sökmen M, et al. (2004). In vitro antimicrobial and antioxidant activities of the essential oils and various extracts of Thymus eigii M. Zohary et P.H. Davis. J Agric Food Chem 52:1132-7.

Tobudic S, Kratzer C, Lassnigg A, et al. (2010a). In vitro activity of antifungal combinations against Candida albicans biofilms. J Antimicrob Chemother 65:271-4.

Tobudic S, Lassnigg A, Kratzer C, et al. (2010b). Antifungal activity of amphotericin B, caspofungin and posaconazole on Candida albicans biofilms in intermediate and mature development phases. Mycoses 53: 208-14.

Tomás-Barberán F, Iniesta-Sanmartín E, Tomás-Lorente F, Rumbero A. (1990). Antimicrobial phenolic compounds from three Spanish Helichrysum species. Phytochemistry 29:1093-5.

Torosantucci A, Bromuro C, Chiani P, et al. (2005). A novel glycoconjugate vaccine against fungal pathogens. J Exp Med 202:597-606.

Tortorano AM, Pemam J, Bernhardt H, et al. (2004). Epidemiology of Candidaemia in Europe: results of 28-month European Confederation of Medical Mycology (ECMM) hospital-based surveillance study. Eur J Clin Microbiol Infect Dis 23:317-22.

Tramsen L, Beck O, Schuster FR, et al. (2007). Generation and characterization of anti-Candida $\mathrm{T}$ cells as potential immunotherapy in patients with Candida infection after allogeneic hematopoietic stem-cell transplant. J Infect Dis 196:485-92.

Trick WE, Fridkin SK, Edwards JR, et al. (2002). Secular trend of hospital-acquired Candidemia among intensive care unit patients in the United States during 1989-1999. Clin Infect Dis 35: 627-30.

Tumvarello M, Posteraro B, Trecarichi EM, et al. (2007). Biofilm production by Candida species and inadequate antifungal therapy as predictors of mortality for patients with Candidemia. J Clin Microbiol 45:1843-50.

Uppluri P, Nett J, Heitman J, Andes D. (2008). Synergistic effect of calcineurin inhibitors and fluconazole against Candida albicans biofilms. Antimicrob Agents Chemother 52:1127-32.

Usacheva MN, Teichert MC, Biel MA. (2001). Comparison of the methylene blue and toluidine blue photobactericidal efficacy against gram-positive and gram-negative microorganisms. Lasers Surg Med 29:165-73.

Van de Veerdonk FL, Netea MG, Joosten LA, et al. (2010). Novel strategies for the prevention and treatment of Candida infections: the potential of immunotherapy. FEMS Microbiol Rev 34:1063-75.

Van Eijk M, Van Roomen CPAA, Renkema GH, et al. (2005). Characterization of human phagocyte-derived chitotriosidase, a component of innate immunity. Int Immunol 17:1505-12.

Vazquez JA, Gupta S, Villanueva A. (1998). Potential utility of recombinant human GM-CSF as adjunctive treatment of refractory oropharyngeal Candidiasis in AIDS patients. Eur J Clin Microbiol Infect Dis 17:781-3.

Vincent J, Anaissie E, Bruining H, et al. (1998). Epidemiology, diagnosis and treatment of systemic Candida infection in surgical patients under intensive care. Intensive Care Med 24:206-16.

Viscoli C, Girmenia C, Marinus A, et al. (1999). Candidemia in cancer patients: a prospective, multicenter surveillance study by the invasive fungal infection group (IFIG) of the European Organization for Research and Treatment of Cancer (EORTC). Clin Infect Dis 28: 1071-9.

Viviani MA. (1995). Flucytosine - what is its future? J Antimicrob Chemother 35:241-4.

Wainwright M. (1998). Photodynamic antimicrobial chemotherapy (PACT). J Antimicrob Chemother 42:13-28.

Wainwright M, Crossley KB. (2002). Methylene blue - a therapeutic dye for all seasons? J Chemother 14:431-43.

Ward GD, Watson IA, Stewart-Tull DES, et al. (1996). Inactivation of bacteria and yeasts on agar surfaces with high power Nd: YAG laser light. Lett Appl Microbiol 23:136-40.

Wenzel RP. (1995). Nosocomial Candidemia: risk factors and attributable mortality. Clin Infect Dis 20:1531-4.

Wey SB, Mori M, Pfaller MA, et al. (1989). Risk factors for hospitalacquired candidemia: a matched case-control study. Arch Intern Med 149:2349-53.

White TC, Holleman S, Dy F, et al. (2002). Resistance mechanisms in clinical isolates of Candida albicans. Antimicrob Agents Chemother 46:1704-13.

White TC, Marr KA, Bowden RA. (1998). Clinical, cellular, and molecular factors that contribute to antifungal drug resistance. Clin Microbiol Rev 11:382-402.

Williams DW, Kuriyama T, Silva S, et al. (2011). Candida biofilms and oral candidosis: treatment and prevention. Periodontology 55: 250-65.

Williams JA, Pearson GJ, Colles MJ, Wilson M. (2003). The effect of variable energy input from a novel light source on the photoactivated bactericidal action of toluidine blue $\mathrm{O}$ on Streptococcus Mutans. Caries Res 37:190-3.

Willment JA, Lin H-H, Reid DM, et al. (2003). Dectin-1 expression and function are enhanced on alternatively activated and GM-CSF-treated macrophages and are negatively regulated by IL-10, dexamethasone, and lipopolysaccharide. J Immunol 171:4569-73.

Wilson M, Donson J, Harvey W. (1992). Sensitization of oral bacteria to killing by low-power laser radiation. Curr Microbiol 25:77-81.

Wilson M, Mia N. (1993). Sensitisation of Candida albicans to killing by low-power laser light. J Oral Pathol Med 22:354-7. 
Wisplinghoff H, Bischoff T, Tallent SM, et al. (2004). Nosocomial bloodstream infections in US hospitals: analysis of 24,179 cases from a prospective nationwide surveillance study. Clin Infect Dis 39: 309-17.

Xin H, Dziadek S, Bundle DR, Cutler JE. (2008). Synthetic glycopeptide vaccines combining $\beta$-mannan and peptide epitopes induce protection against candidiasis. Proc Natl Acad Sci USA 105:13526-31.

Zaoutis TE, Argon J, Chu J, et al. (2005). The epidemiology and attributable outcomes of Candidemia in adults and children hospitalized in the United States: a propensity analysis. Clin Infect Dis 41:1232-9.

Zhang J-D, Xu Z, Cao Y-B, et al. (2006a). Antifungal activities and action mechanisms of compounds from Tribulus terrestris $\mathrm{L}$. J Ethnopharmacol 103:76-84.

Zhang MX, Bohlman MC, Itatani C, et al. (2006b). Human recombinant antimannan immunoglobulin G1 antibody confers resistance to hematogenously disseminated Candidiasis in mice. Infect Immun $74: 362-9$. 